\title{
39. Retention of Virus by its Insect Vectors through Several Generations.*
}

\author{
By Teikichi Fukushi. \\ Botanical Institute, Faculty of Agriculture, \\ Hokkaido Imperial University, Sapporo. \\ (Comm. by K. MiYaBe, M.I.A., May 12, 1939.)
}

In a previous paper" the writer has reported on a case of successful transmission of the virus of rice dwarf disease through the eggs of its insect vector passing on to the progeny of the 3rd generation. In view of the fact that rice dwarf disease occupies a unique position among plant virus diseases on account of its transmissibility through the eggs of a certain insect vector, an attempt was made to study this phase of the problem more extensively as a part of the investigations conducted on the special relationship between the virus of this disorder and its insect carrier, Nephotettix apicalis cincticeps, a leafhopper. The experimental procedure was similar to what has previously been described. It consists of picking up the nymphs bred from infective female leafhoppers immediately upon hatching to cage them singly. on healthy rice seedling plants and subsequently transferring them daily to successive new healthy plants. The viruliferous females found among these 2nd generation individuals are paired with non-viruliferous males and their offspring are also transferred to healthy plants as soon as they have hatched. Subsequently they are likewise transferred daily to successive new healthy plants in order to keep them from renewed access to a source of infection. In a similar way the experiment was continued as long as a viruliferous female was available in the progeny of the leafhoppers. As a consequence, during the past 5 years, two cases each were secured of transmission of the virus through eggs to the progeny of the 3rd and 4th generations as well as one case of its perpetuation to the 7 th generation. In each case the experiment was unavoidably ended because of the circumstances that either viruliferous females could not be obtained or that they died before laying eggs. The results of these experiments are presented in the following diagrams and table.

The writer wishes to acknowledge gratefully his indebtedness to Profs. K. Miyabe and S. Ito for their kind advice and encouragement throughout the course of the investigation.

* This work was made possible, in part, through a grant from the Japan Society for the Promotion of Scientific Research.

1) Fukushi, T.: Multiplication of virus in its insect vector. Proc. 11 (1935), 301-303. 
No. 5.] Retention of Virus by its Insect Vectors through Several Generations.

(I)

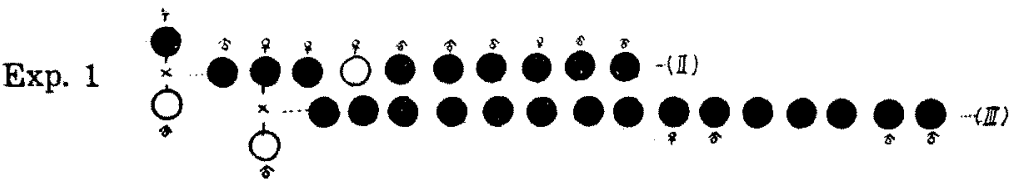

(I)

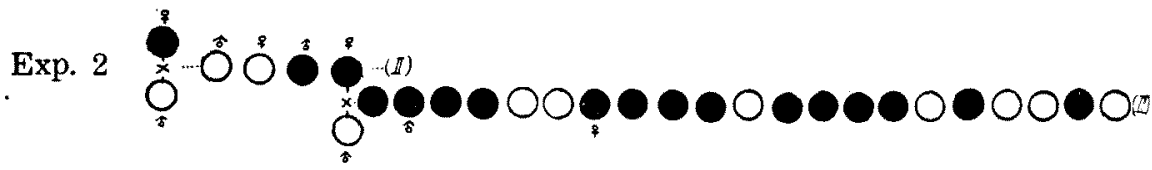

(I)

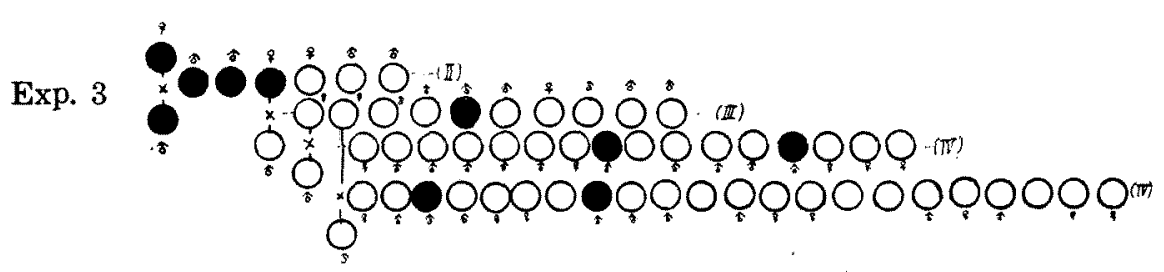

(I)

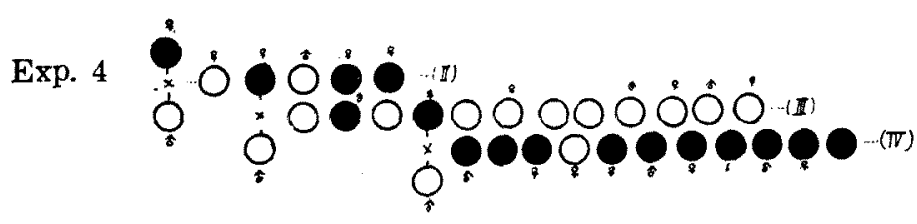

(I)

Exp. 5

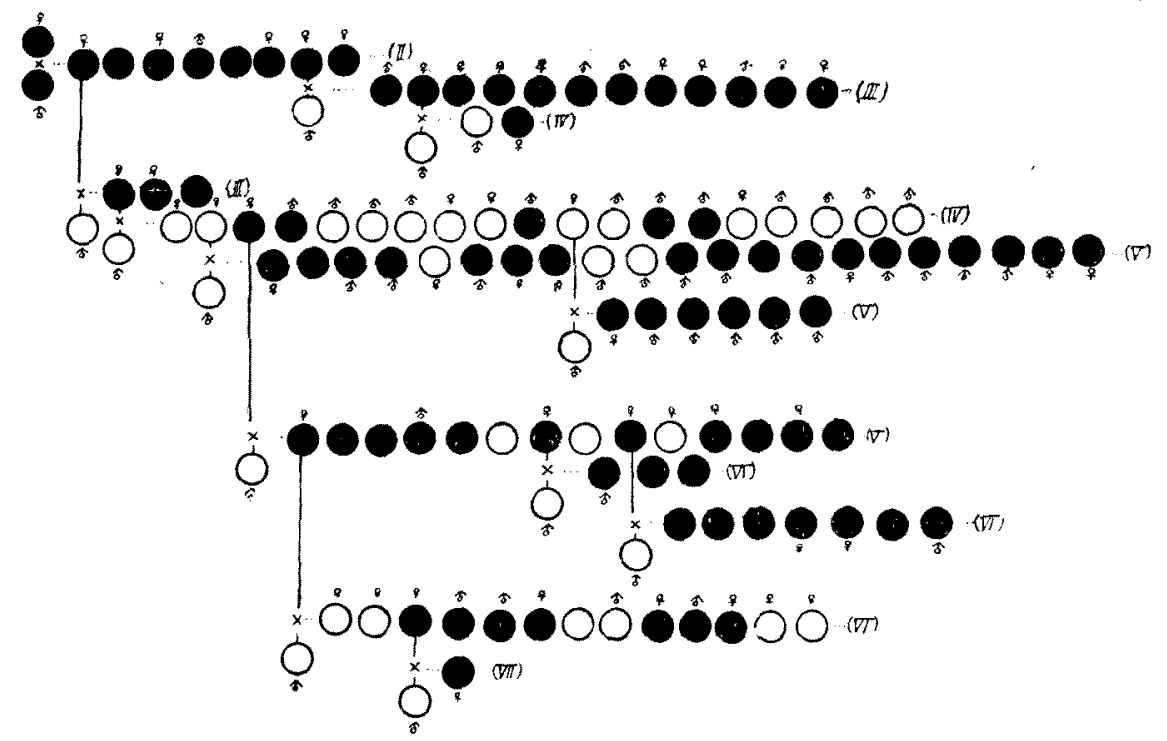

- indicate infective and non-infective leafhoppers, respectively. 


\begin{tabular}{|c|c|c|c|c|c|c|c|c|c|c|c|c|c|}
\hline \multirow{2}{*}{$\begin{array}{l}\text { Genera- } \\
\text { tion } \\
\text { Experi- } \\
\text { ment } \\
\text { No. }\end{array}$} & \multirow[t]{2}{*}{ I } & \multicolumn{2}{|c|}{ II } & \multicolumn{2}{|c|}{ III } & \multicolumn{2}{|c|}{ IV } & \multicolumn{2}{|c|}{ V } & \multicolumn{2}{|c|}{ VI } & \multicolumn{2}{|c|}{ VII } \\
\hline & & & 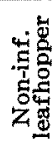 & 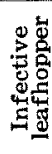 & 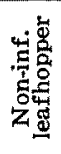 & 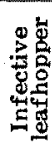 & 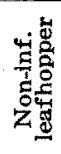 & 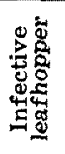 & 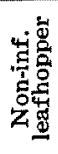 & 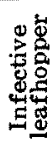 & 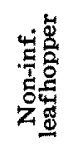 & 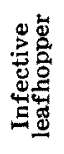 & 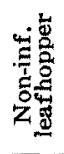 \\
\hline 1 & $+\times 5$ & 9 & 1 & & & & & & & & & & \\
\hline 2 & $9 \times \delta$ & 2 & 2 & & & & & & & & & & \\
\hline 3 & $9 \times 5$ & 3 & & & 9 & & 34 & & & & & & \\
\hline 4 & $9 \times 5$ & 3 & 2 & & 10 & & & & & & & & \\
\hline 5 & $9 \times$ & 8 & 0 & 15 & 0 & & 15 & 36 & 6 & 17 & 6 & 1 & 0 \\
\hline
\end{tabular}

- $\delta$ indicate infective female, infective male and non-infective male, respectively.

It is worthy of note that certain female leafhoppers which proved to be non-infective through their entire life produced infective progeny as shown in experiments 3 and 5 . On this point some explanations seem to be necessary. When a low temperature prevailed in the green house, a much prolonged incubation period was usually required for the virus in the rice plant. On the other hand, some female leafhoppers which had grown too old would show a tendency not to mate readily with males. Accordingly, in experiment 3, certain females of the 3rd generation which had been reared during the winter were allowed to mate with nonviruliferous males without waiting for their betraying infectivity. They eventually proved to be non-infective but some of their offspring produced infections in test plants. This phenomenon which was more definitely established in experiment 5 admits, in the writer's opinion, the following interpretation. Under low temperature conditions which retard the manifestation of the disease in the rice plant, the multiplication of virus may be remarkably inhibited not only in the rice plant but also within the bodies of the insect carrier. In such a case the virus is perhaps more or less localized in its distribution and movement through the insect body. It is possible that in some leafhoppers the virus may migrate to the salivary glands and finally may be injected into the plant tissues through the proboscis to cause infections whereas in other individuals it may localize not in the salivary glands but in ovarian tubules to give rise to viruliferous eggs. Admittedly the latter individuals will prove to be non-infective but may produce infective progeny.

As shown in the diagrams, a most striking instance of prolonged retention of the virus by leafhoppers was obtained in experiment 5 . In this case the virus has been transmitted through the eggs to the progeny of the 7th generation; that is to say it has been retained within insect bodies for a whole year or during the period from April 7, 1938 to April 24, 1939.

It appears that the virus has practically not been reduced in virulence as a result of its retention by insect carriers through several generations, since a majority of the infective leafhoppers of the 6th 
No. 5.] Rentention of Virus by its Insect Vectors through Several Generations. 145

generation produced infections in each 50-80 plants on which they had been confined singly for a day. Four infective females of the 6th generation were paired with nonviruliferous males at a suitable time but three of them deposited no eggs while the remaining one laid only a few normal and several abortive eggs. Only one nymph of the 7th generation could be picked up at the proper time and confined on a test plant without daily transfers, which subsequently developed the signs of infection.

The complete experimental data for the 5 cases mentioned above will be presented in detail in another publication. But it will be interesting to note here that in experiment 5 , infections were produced in more than one thousand rice plants by 26 leafhoppers of 5 generations derived from one viruliferous egg, when they were confined singly on a rice plant for a day and transferred daily to new healthy plants.

To explain these experimental results it seems necessary to assume that the virus of rice dwarf disease multiplies within the bodies of its insect vectors, since the amount of virus originally contained in one egg must be extremely small. 